\title{
Translation and Technology: Investigating the Employment of Computer-aided Translation (CAT) Tools among Iranian Freelance Translators
}

\author{
Hamidreza Abdi \\ Freelance Researcher, Iran
}

\begin{abstract}
The present study aimed to investigate the employment of computer-aided translation (CAT) tools among Iranian freelance translators. Fulford and Granell-Zafra (2005) proposed a model encompassing both information and communications technology (ICT) and CAT tools to support a large number of activities, including document production, information search and retrieval, communications, business management, marketing and work procurement, and translation creation. CAT tools are employed to support document production, business management, and translation creation; and ICT tools are used to support the rest. A questionnaire was used for data collection from Iranian freelancers. As the results indicated, Iranian freelance translators were more interested to employ general-purpose software applications, such as word processing programs and presentation software, whereas they showed less interest in the employment of special-purpose software, such as accounting packages and database software. Moreover, most participants approved the effectiveness of CAT tools in their work.
\end{abstract}

Index Terms - freelance translator, translator's workstation, and computer-aided translation

\section{INTRODUCTION}

Translators require computer competence for the use of computer-aided translation (CAT) tools in their productions. Computer, as a user interface, gives translators the opportunity to utilize translation software, such as CAT tools. CAT tools are probably "the clearest example of translator-specific computer tools designed to increase translators' productivity and efficiency" (Granell, 2015, p. 1). In this regard, Newton (1992, p. xvi) believes that "computerized tools offer tangible benefits in almost every area of written translation." CAT tools alongside automatic systems (Quah, 2006) are the subdivisions of translation technology.

There are two types of translators: in-house and freelance translators. In-house translators are those who work for specific companies as full-time employees. They just translate as they have been asked, and have nothing to do with other activities related to translation. For example, they do not need to worry about managing new clients and customer relations, but freelance translators are self-employed people who own their own business. It implies that "being a freelance translator also means taking on additional tasks" (Granell, 2015, p. 18). Hence, freelance translators should cope with all translation activities alone. That is to say, the degree of using CAT tools is heavily dependent on the type and role of the translator in the translation process.

Along with translation competence, the freelance translator requires technology competence. This includes "all the knowledge and skills used to implement present and future translation technologies within the translation process" (EMT Network, 2017, p. 9); however, translation competence, which itself covers seven sub-competences, is "the underlying system of knowledge and skills needed to be able to translate" (PACTE Group, 2000, p. 100). There are also issues related to language and culture, personal and interpersonal, and service provision competences. One advantage of technology competence is that it enables the translator to have the effective use of CAT tools. This not only affects the quality of the translators but also helps them to produce high-quality translations. S. Koby et al. $(2014$, p. 416$)$ defined a high-quality translation as follows:

A high-quality translation is one in which the message embodied in the source text is transferred completely into the target text, including denotation, connotation, nuance, and style, and the target text is written in the target language using correct grammar and word order, to produce a culturally appropriate text that, in most cases, reads as if originally writ-ten by a native speaker of the target language for readers in the target culture.

It seems that most Iranian freelance translators have not yet reached a reasonable level of technology competence for many reasons. The first reason might be related to the fact that the traditional methods, such as paper dictionaries and type writers as well as the old versions of personal computers (PCs), are still used by translators. Meanwhile, fax and conventional postal systems are still a common way of communication. The weakness of education system in training translators and the academic courses offered by universities, in both postgraduate and undergraduate levels, are considered the second reason. 
It should be noted that translation most universities offer courses that mainly cover translation theories rather than translation practices, and the courses related to CAT tools are not included, despite their effectiveness and importance in producing high-quality and cost-effective translations (see for example, Sharif, 2016; Hazbavi, 2011). Furthermore, most syllabuses taught at universities are outdated and ineffective. The limited number of teachers and high price of private training courses have also aggravated the situation.

During the history of using conventional translation tools, "translation technology has come to stay and the good old days of pen-and-paper translation are inevitably coming to an end" (Krüger, 2016, p. 114). It means rather that in recent years, significant changes have occurred more quickly in the translation industry. The development of technology is going to escalate with an incredible speed and the translators' demands are going to depend on using CAT tools. Furthermore, translation is "starting to become a big business, increasingly integrating as suppliers the traditional cottage industry of freelances" (Mossop, 2006, p. 789). Therefore, translators need to shift their approaches towards the use of technological tools, namely ICT and CAT tools; otherwise, they will become uncompetitive (Samuelsson-Brown as cited in Bowker, 2002). This implies that the use of CAT tools not only gives translators the opportunity to save time and energy but also affects the quality of their translations. That is to say, translation technology, as Krüger argued, has a powerful effect on both the nature of the translation process and the translator's cognition. This claim is well defined by Pym (2011, p. 1) as follows:

New translation technologies such as translation memories, data-based machine translation, and collaborative translation management systems, far from being merely added tools, are altering the very nature of the translator's cognitive activity.

Accordingly, this study was carried out to investigate the use of CAT tools by Iranian freelance translators. It also attempted to create a new attitude towards the employment of modern technological tools, like CAT tools, among Iranian freelancers and specify how these tools are significant for them in order to be taken into consideration by those responsible for the educational system and for the translation industry in Iran.

To conduct the study, the researcher decided to divide translation activities presented by Fulford and Granell-Zafra (2005) into two groups. This phase of study covered the second group of activities which were supported by the use of CAT tools. This includes document production, business management, and translation creation.

The study reported the findings of the second phase of the research project. This phase contained an exploratory survey of the employment of CAT tools among Iranian freelance translators. It is hoped that the findings of the present study can offer helpful suggestions for translation students, trainee translators, novice freelancers, and those responsible for the spread of CAT tools knowledge. To achieve the objective of the second phase of the project, the following question was raised:

1. What is the extent of employing CAT tools among Iranian freelance translators?

\section{REVIEW OF THE RELATED LITERATURE}

The history of CAT tools goes back to the 1990s when the intersecting input of machine translation and computational terminology provided considerable benefits to CAT (Delpech, 2014), and "they have not yet extensively documented in translation textbooks" (Bowker, 2002, p. 6). Bowker believed that CAT technology refers to any computer-based tool used by translators as an aid in their job. CAT tools are the computer-based software used by the translators to support the translation process (Hutchins \& Somers, 1992). Such tools "are aggressively marketed to professional translators and the unique features of a tool are usually highlighted" (Quah, 2006, p. 131). Various terms have been used for CAT tools, such as electronic translation tools (Austermühl, 2001), machine-aided translation (Quah, 2006), and translation software (Hutchins, 2009). It is rather to say, CAT tools refer to a pack of applications that express the notion about computer assistance, which is at the service of translators (Carmo et al., 2016).

In recent years, CAT tools are of interest to translation providers in such a way that they make use of CAT technology to increase their productivity (Taravella \& O. Villeneuve, 2013). Translators unavoidably encounter with the problematical issues, including the integrity of data with lower standards, when they are aiming at using standard CAT tools, namely spreadsheet, database, or word processing programs since the characteristics of modeling are not appropriate, as well as difficulties to manage a bulk amount of information as resources increase gradually (Schmitz as cited in Bowker, 2002). Bowker noted that this problem is going to be solved by using terminology management systems which are placed as the first important tools in the set of CAT tools.

CAT tools were used to support "a translator's workstation" found many years ago in the field of translation and technology. From the early 1980s up to now, many classifications have been used to define the translator's workstation (see for example Melby, 1982; Hutchins \& Somers, 1992; Hutchins, 1998; and Locke, 2005). Later on, various types of CAT tools and language resources were available to and provided many facilities for translators. This ranges from "word processing facilities, through dictionary look-up tools, systems for creating and managing terminology collections, to translation memory and machine translation" (Fulford \& Granell-Zafra, 2004, p. 53). Along with the above mentioned classifications, Fulford and Granell-Zafra (2005) presented their own classification of the translator's workstation which was different from the previous ones. The advantage of their model was that it considered not only CAT tools but also ICT tools which both required to be employed by the freelance translators to support a wide range of translation activities. Moreover, as Granell (2015) cited, previous models have concentrated on translators' linguistic 
activities. Their model supports: document production, information search and retrieval, communications, business management, marketing and work procurement, and translation creation activities (as cited in Granell).

Many empirical studies have been conducted to investigate the use of technology in translation (e.g. Muñoz, 2010; Arenas, 2013; Alonso, 2015). Some have been focused on processes and software applications (O'Brien et al, 2014), whereas some others have paid attention to different types of translation tools, such as terminology management tools (Martikainen, 2018), machine translation (Tantuğ \& Adal1, 2018), and translation memories (Christensen \& Schjoldager, 2017). Along with such studies, there were some recent studies which focused on translator curriculum and university training courses (see Cifuentes-Goodbody \& Harding, 2016; Ketola \& García-Escribano, 2018) as well as on the translator's workstation (Alonso \& Vieira, 2017).

In spite of many studies in the field, the freelance translator community has not been taken into consideration by the researchers in Iran. A few recent studies have paid attention to various types of translation tools. For example, translation memory tools have been considered by Sabet et al. (2016), machine translation by Maleki and Tabrizi (2017), and translator curriculum by Shahri and Farimani (2016). CAT tools as a type of translation technological tool for translation have also been considered by several studies (see for example Khadivi \& Vakil 2012; Taghizadeh \& Azizi, 2017; Akbari, 2018). Besides, translation profession in Iran comprehensively investigated by Kafi et al. (2018).

Although recent studies in the field were constructive in their own right and addressed some existing gaps in the research, they did not cover a wide range of CAT tools and the translators' working practices. They did not also select the participants of their studies from freelance translators, i.e., they mostly considered other types of translators, such as in-house translators and translation students. Moreover, all translation activities included in the translator's workstation were not widely covered and the considerations were limited to one or two translation activities. In this regard, although Akbari's (2018) study covered many translation activities and was constructive and helpful in improving translation industry in Iran, he ignored freelance translators and merely selected translation students as the participants. There is the same problem in the study conducted by Taghizadeh and Azizi (2017).

Khadivi and Vakil (2012) considered only one type of translation activity in their study, such as translation production. The importance of including CAT tools in translation programs was not emphasized by Kafi et al. (2018) although they put the emphasis on revising the current syllabus of Translation Studies. This issue should to be taken into consideration because of that the knowledge of CAT tools employment is a type of technology competence that each translator needs to acquire. The main advantage of this study over previous ones is that it not only pays a special attention to the freelance translator community but also covers various translation activities supported by CAT tools. Moreover, the important role CAT tools play in productivity of freelance translators is highlighted.

\section{METHOD}

\section{A. Participants}

The participants of this study were freelance translators who answered the questionnaire. It should be noted that the same participants in the first phase of the research project participated in the second phase, but a few of them did not answer the questionnaire. That is why the number of participants in this phase $(N=256)$ was lower than the number in the first phase $(N=287)$. Moreover, the number of females $(n=158)$ was more than the number of males $(n=98)$.

\section{B. Instrument}

The questionnaire was used for data collection from the participants of the study. To design the questionnaire, the researcher studied different books, such as Researching second language classrooms (McKay, 2006) and Research in education (Best \& Kahn, 2006), to take note from helpful suggestions. The constructive suggestion for designing the questionnaire was made from the questionnaire that was used in the same study conducted by Fulford and Granell-Zafra (2005) on UK freelance translators. A panel of experts in the field was asked to establish validity of the questionnaire. Feedbacks and comments led to some corrections in the wording of several questions and the structure of the questionnaire.

Reliability of the questionnaire was assessed through a test-retest procedure. Thus, it was administrated to 20 freelance translators who shared the same characteristics of the sample of the study. After two weeks, it was applied to the same freelancers under the same condition. The results of the two trials were correlated and the coefficient of correlation represented the reliability of the test $(r=.841)$. The questionnaire used in this phase was organized into the following parts:

\section{- Part I: Personal details}

This section covers questions about background information of the participants, such as age, gender, and educational degree, the characteristics of their translation business, and computer knowledge of the participants.

- Part II: CAT tools employment

This part contains questions related to CAT tools employed by the participants to support the second group of translation activities, including document production, business management, translation creation, and participants' opinions about CAT tools employed in their translation workflow. 
As the list of Iranian freelance translators was available on the Internet (www. motarjeman.org), the mailed questionnaire method was employed. In this way, the questionnaire was sent to the participants whose email addresses were available on their profiles, and all responses were received through email too.

\section{Design}

In order to investigate the employment of CAT tools among Iranian freelance translators, many methods were available for the researcher, such as surveys and case studies. The superiority of surveys over other types was that they enable researchers to collect large amounts of data with low price in a short time with low price (Dornyei as cited in McKay, 2006). Four types of surveys were presented by Bryman and Bell (2003), including questionnaires, interview, observation studies, and content analyses. Among these four types of survey, the questionnaire type was an appropriate method for data collection in the present study. The reason is that it provided the opportunity for the researcher to collect data from a large number of Iranian freelancers from all around the country with lower price in a shorter time than other types.

\section{RESUlT AND DisCUSSION}

This section provides the results of the first part of the questionnaire. In order to analyze the data of this study, each question was analyzed separately and the characteristics of the participants were described. The important findings derived from the questionnaire are discussed below.

\section{A. Personal Details of the Participants}

This section includes some demographic information of the participants as follows: The age distribution of the participants was 20-29 years (53\%), 30-39 years (28\%), 40-49 years (13\%), 50-59 years (4\%), and $60+$ years (2\%). Less than half of the participants (46\%) had an MA degree, 32\% had a BA, \% 16 had an associate's degree (AD), and $6 \%$ held a PhD. Most participants (81\%) held educational degrees related to translation studies (39\% had an MA, 27\% a $\mathrm{BA}, 12 \%$ an $\mathrm{AD}$, and $3 \%$ a $\mathrm{PhD})$. The rest of participants $(19 \%)$ held educational degrees unrelated to translation studies. As the results showed, a high proportion of participants $(78 \%)$ had less than 10 years of experience working as freelance translators (35\% between 1 to 4 years, and $43 \%$ between 5 to 9 years), $19 \%$ had between 10 to 20 years' translation experience, and $3 \%$ had more than 20 years of experience.

Also $11 \%$ of the participants dedicated 30 hours to translation-related tasks each week. Furthermore, the average participants spent on translation-related tasks each week was 68 hours. More than two-thirds of the participants (87\%) offered no additional services other than translating, a few (13\%) offered additional services of whom $30 \%$ were engaged in language training activities as well.

The most translated language pairs (43\%) were Persian to English and English to Persian, followed by Persian to French and French to Persian (26\%) as well as Persian to German and German to Persian (18\%). The remainder (12\%) included a number of language pairs, namely Persian to Turkish and Turkish to Persian, and Persian to Arabic and Arabic to Persian. Marketing and advertising translation (18\%), and legal translation (13\%) were the most/least translation subject areas which freelance translators were expert in, respectively.

Two-thirds (75\%) of the participants had surprisingly acquired their computer skills via "self-taught", which was much higher than the frequency of other methods. Moreover, $26 \%$ of the freelance translators had obtained any form of formal qualification in computer.

\section{B. Computer-aided Translation Employment}

The second part of the questionnaire included questions about the usage of software applications. In this section, the important findings related to document production, business management, and translation creation are reported in brief. The details of CAT tools employment alongside the details of types of each software application and the activities supported are provided in tabulation forms.

1. Document Production Activities

According to table 1, word processing and presentation programs were in widespread use to support document production activities (100\% of the participants used word processing software and $86 \%$ employed presentation software). Among word processing software, MS word (59\%) was the most popular program, followed by Microsoft Notepad (18\%), Google Docs (14\%), and Corel WordPerfect (9\%). From different types of presentation software, MS PowerPoint was used by $57 \%$ of the participants, and ClearSlide Edge by (20\%). Other types included $13 \%$ Haiku Deck, $8 \%$ ClearSlide, and 3\% Prezi. Web publishing was used by two-thirds of the participants (75\%). The mostly used web publishing programs in order of frequency were: MS FrontPage (61\%) and Google Web Designer (17\%). Desktop publishing was used less than other types of document production activities (37\% of the participants employed them). 
TABLE I.

DOCUMENT PRODUCTION ACTIVITY

\begin{tabular}{|l|l|c|c|c|}
\hline \multicolumn{2}{|c|}{ Types } & $f$ & Total & $\%$ \\
\hline Word processing software & & 256 & 256 & 100.0 \\
\hline & MS word & 150 & 256 & 59.0 \\
\hline & Microsoft Notepad & 47 & 256 & 18.0 \\
\hline & Google Docs & 37 & 256 & 14.0 \\
\hline & Corel WordPerfect & 22 & 256 & 9.0 \\
\hline Presentation software & & 219 & 256 & 86.0 \\
\hline & MS PowerPoint & 124 & 219 & 57.0 \\
\hline & ClearSlide Edge & 43 & 219 & 20.0 \\
\hline & Haiku Deck & 29 & 219 & 13.0 \\
\hline & ClearSlide & 17 & 219 & 8.0 \\
\hline & Prezi & 6 & 219 & 3.0 \\
\hline Web publishing software & & 192 & 256 & 75.0 \\
\hline & MS FrontPage & 118 & 192 & 61.0 \\
\hline & Google Web Designer & 33 & 192 & 17.0 \\
\hline & Adobe Dreamweaver & 19 & 192 & 10.0 \\
\hline & Bluefish & 11 & 192 & 6.0 \\
\hline & Atom Text Editor & 9 & 192 & 5.0 \\
\hline & Webflow & 2 & 192 & 1.0 \\
\hline Desktop publishing software & & 94 & 256 & 37.0 \\
\hline & Adobe InDesign Online & 33 & 94 & 35.0 \\
\hline & Microsoft Publisher & 24 & 94 & 26.0 \\
\hline & LibreOffice Draw & 18 & 94 & 19.0 \\
\hline & FlipHTML5 & 13 & 94 & 14.0 \\
\hline & Other & 6 & 94 & 6.0 \\
\hline Total activity employment & & 752 & 1024 & 74.0 \\
\hline
\end{tabular}

2. Business Management Activities

As table 2 indicates, the participants of this study preferred to employ spreadsheet software more than other programs to support business management activities. In other words, $76 \%$ of freelance translators used spreadsheet software of which MS Excel (41\%) and Office 365 (35\%) were the mostly used ones. About one-third of the participants (34\%) used database software applications of whom $42 \%$ used MS Access and 35\% employed FileMaker. A very small number of the participants $(16 \%)$ employed other types of database software $(10 \%$ used Team Desk, $3 \%$ employed TablePlus, and $3 \%$ applied Knack). According to the results, $29 \%$ of the freelance translators were interested to use database software. From accounting packages, more than half of the participants (51\%) used Sage; whereas a few number of them (11\%) employed FreshBooks.

TABLE II.

BUSININES MANAGEMENT ACTIVITY

\begin{tabular}{|l|l|c|c|c|}
\hline \multicolumn{2}{|c}{ Types } & $f$ & Total & $\%$ \\
\hline Spreadsheet software & & 201 & 256 & 76.0 \\
\hline & MS Excel & 82 & 201 & 41.0 \\
\hline & Office 365 & 71 & 201 & 35.0 \\
\hline & Google Sheets & 21 & 201 & 10.0 \\
\hline & Lotus 1-2-3 & 14 & 201 & 7.0 \\
\hline & Numbers & 8 & 201 & 4.0 \\
\hline Database software & WPS Office & 5 & 201 & 3.0 \\
\hline & & 88 & 256 & 34.0 \\
\hline & MS Access & 42 & 88 & 48.0 \\
\hline & FileMaker & 31 & 88 & 35.0 \\
\hline & Team Desk & 9 & 88 & 10.0 \\
\hline & TablePlus & 3 & 88 & 3.0 \\
\hline Accounting packages & Knack & 3 & 88 & 3.0 \\
\hline & & 74 & 256 & 29.0 \\
\hline & Sage & 38 & 74 & 51.0 \\
\hline & QuickBooks & 28 & 74 & 38.0 \\
\hline Total activity employment & FreshBooks & 8 & 74 & 11.0 \\
\hline & & 363 & 768 & 47.0 \\
\hline
\end{tabular}

3. Translation Creation Activities

In order to support translation creation activities, the great majority of the participants (93\%) employed machine translations. Google Translate (77\%) was the mostly used tool among Iranian freelancers; Microsoft Translator was in the second place employed by $34 \%$ of the participants; and translation memories (TM) were not very popular used by less than half of the participants (43\%). From available translation memories, Trados and SDLX were the most famous ones used by $37 \%$ and $31 \%$ of the participants, respectively. The other types were used by $32 \%$ of the participants (Déjà $\mathrm{Vu}$ used by $25 \%$, and Babylon Translator employed by $7 \%$ of the participants). 
TABLE III.

TRANSLATION CREATIVE ACTIVITIES

\begin{tabular}{|l|l|l|l|l|}
\hline \multicolumn{2}{|c|}{ Types } & $f$ & Total & $\%$ \\
\hline Machine Translations & & 238 & 256 & 93.0 \\
\hline & Google Translate & 183 & 238 & 77.0 \\
\hline & Microsoft Translator & 34 & 238 & 14.0 \\
\hline & MateCat & 16 & 238 & 7.0 \\
\hline & Apertium & 5 & 238 & 2.0 \\
\hline Translation Memories & & 110 & 256 & 43.0 \\
\hline & Trados & 41 & 110 & 37.0 \\
\hline & SDLX & 34 & 110 & 31.0 \\
\hline & Déjà vu & 27 & 110 & 25.0 \\
\hline Total activity employment & Babylon Translator & 8 & 110 & 7.0 \\
\hline
\end{tabular}

\section{Iranian Freelance Translators' Perceptions of CAT Tools}

The last question was about the participants' perception about CAT tools. In a sense, Iranian freelance translators were asked for their opinions about the role of such tools in their work. In general, participants were in full agreement about the significant role CAT tools play in translation activities, namely document production, business management, and translation creation and they had positive perceptions of considerable influence of such tools on their work. Almost all participants shared the belief that CAT tools were easy to use and should be replaced by traditional methods, such as paper dictionaries and typewriters; they also agreed that the productivity and efficiency of translators are strongly dependent on the use of such tools. The great majority were in agreement about the fact that CAT tools make the process of translation easier in the attempt to produce high quality translations with a lower price and shorter time. Moreover, a high portion of the freelancers believed that in order to become more competitive in today's market, they need to employ CAT tools in their work.

\section{Discussion}

In the previous section, the results obtained from the questionnaire were presented. This section discusses the important findings of each part of the questionnaire separately.

The first part of the questionnaire reported some important findings, one of which was the method of computer skills acquisition that Iranian freelancers employed. Most participants applied "self-taught" method to develop their skills in working with computer. This finding can be either positive or negative. The positive side demonstrates the remarkable ability of freelancers to acquire such a skill via self-taught. This may be due to the bad economic condition of Iranian freelancers. The negative side is that each skill needs to be learned properly and accurately, that is, the skill of working with computer should be taught by an expert in the field.

According to the results, the great majority of the participants held the educational degree related to translation (half of them held an MA degree in translation studies). This refers to the academic knowledge of the freelancers and their familiarity with translation theories and methods. Absolutely, this has significant effects on their productions. The results indicated that most translators had mastery over a few language pairs, such as English to Persian and Persian to English, and French to Persian and Persian to French. The domestic market is in need of more than one or two language pairs because of many reasons, such as having more customers and being competitive in today's market.

Undoubtedly, MS Word is the most popular and easy-to-use software in Iran. That is why MS Word was the first mostly used word processing software. The same results were derived from the study done by Fulford and GranellZafra (2005). The UK freelance translators preferred to use word processing software more than other programs to support document production activities. Along with MS Word, there was MS PowerPoint as another popular presentation program because of the facilities it provides for the users, such as working with others without wasting time, giving the user easy and quick access to the presentations from different locations and on more devices, making high quality presentations with impressive graphics, and enabling the user to do things faster. Surprisingly, a few number of UK freelancers employ MS PowerPoint.

Spreadsheet software, including MS Excel and Office 365, were of more interest to Iranian freelancers than other programs to support business management activities. The reason is that they are easy-to-use and cost-effective programs. The unsatisfactory results were the least use of database software and accounting packages. These programs offer many advantages to the freelance translators. For example, the most important advantage of accounting packages is that they save a lot of time over traditional methods, namely, manual bookkeeping. You are also able to create invoices for your clients and make bank deposits ready for use. In addition, all transactions are recorded by the system for you. UK freelance translators expressed the same opinion about the employment of spreadsheet software and accounting packages. These applications were the most/least used software, respectively.

As the results indicated, Iranian freelancers tended to employ machine translations, such as Google Translate, to support translation creation activities. As expected, non-web-based machine translations, such as Microsoft Translator, were the most popular programs because they could be employed in the absence of the Internet. This can be a 
significant advantage that needs to be taken into consideration by the freelancers in Iran. Using web-based programs may create some problems not only for Iranian freelancers but also all Iranian internet users. This may be due to the filtering policy that produces negative effects on the quality and speed of the Internet in Iran.

Fortunately, Iranian freelance translators had a positive attitude towards CAT tools. They have come up with the notion about the significant role of such tools in translation. This implies a change in their opinions from the use of traditional methods to modern ones that causes them to become more productive and efficient. That is why this change can be positive for both freelance translators and other types of translators, such as in-house translators and translation student.

In general, according to the findings of this study, the preference of Iranian freelance translators was to employ general-purpose applications more than specific-purpose ones to support a wide range of activities included in the freelance translator's workflow. This may be because of the fact that such applications are not used only to support the activities restricted to translation, such as translation creation. By contrast, there were limited employments of specialpurpose software. This might be due to the fact that the participants were unaware of the benefits or had no knowledge of using such software, for example Non-web- based machine translations and accounting packages. Furthermore, the employment of special-purpose applications is exclusive to freelance translator-specific activities, namely translation creation and business management. Thus, these applications need to be used to support such specific activities.

\section{CONCLUSION AND IMPLICATION}

CAT tools are effective and essential tools which have not been considered seriously by the recent studies in Iran. Furthermore, Iranian freelance translators and their employment of CAT tools have not been investigated by Iranian researchers so far. The importance of this investigation is because of the significant role CAT tools play in supporting translation activities that help freelance translators to produce high-quality and cost-effective translations, and remain competitive in the market. This is because of the rapid growth of technology in the field and the large-scale production of applications, both general-purpose and translation-specific. Hence, the high use of CAT tools can help translators not only to improve their productivity but also their customer relations. Unfortunately, the employment of CAT tools among the majority of Iranian freelancers was low to the extent that they were restricted to general-purpose software, such as word processing programs and presentation software, which cannot be good news for the community of freelance translators.

According to the findings of this study, some pedagogical implications were identified for those responsible for the spread of CAT tools knowledge, translation students, trainee translators, and novice freelancers. These implications are discussed below.

The main focus of translation courses in Iran is on theoretical and linguistic issues rather than on practical aspects. Courses related to technological tools, such as CAT tools and ICT tools, are not offered, and qualified professors in the field are not employed. Thus, it is recommended that those responsible for the improvement of CAT tools knowledge, including the Ministry of Science, Research and Technology, pay special attention to Iranian universities and translator training associations because they are in need of modern software and hardware facilities.

The education system that is responsible for training translators is in need of fundamental changes in its structure, from admission to graduation. In a wider sense, student admission criteria of universities in Iran are really outdated and inefficient. The education system needs to come up with some new criteria based on actual needs of the domestic market. For example, the number of admitted students in academic levels can be changed every three years.

Besides, the syllabuses taught at universities are outdated and need to be revised. It is suggested that instructors and translation teachers use new materials and design syllabuses based on them. Furthermore, translation courses offered to students cannot help them to improve their productivity because they are old-fashioned and need re-adjustment. For example, courses related to ICT and CAT tools should be offered as compulsory courses.

It is suggested that translation students, trainee translators, and novice freelance translators mainly focus on generalpurpose applications, such as MS Word and MS PowerPoint, and acquire the knowledge of working with them. After a period of time, they can employ special-purpose software, such as SDLX and QuickBooks. They attend seminars and workshops held by professional translators and qualified teachers on the latest development of technology to improve their technology competence. Last but not least, they should bear in mind that if they want to remain completive, produce high quality translations, and meet the needs of today's market they need to enhance all competency items defined by EMT Network (2017).

\section{REFERENCES}

[1] Akbari, A. (2018). Students' translations and the use of online-resources: Do online resources contribute Iranian trainee translators? SKASE Journal of Translation and Interpretation 11.1, 2-23.

[2] Alonso, E. (2015). Analyzing translation professionals in the information society and their use and perceptions of Wikipedia. The Journal of Specialized Translation 23, 89-116.

[3] Alonso, E. \& Vieira, L. (2017). The translator's amanuensis 2020. The Journal of Specialized Translation 28, 345-361.

[4] Arenas, A. G. (2013). What do professional translators think about post-editing? The Journal of Specialized Translation 19, 75-95. 
[5] Bowker, L. (2002). Computer-aided translation technology: A practical introduction. Canada: University of Ottawa Press.

[6] Bryman, A. \& Bell, E. (2003). Business research methods. Oxford: Oxford University Press.

[7] Cifuentes-Goodbody, N. \& Harding, S. (2016). An integrated approach to the translation studies curriculum. Current Trends in Translation Teaching and Learning 3, 1-23.

[8] Christensen, T. P. \& Schjoldager, A. (2017). Translation-memory (TM) research: What do we know and how do we know it? Hermes - Journal of Language and Communication in Business 23.44, 89-101.

[9] Delpech, E.M. (2014). Comparable corpora and computer-assisted translation. London: ISTE Ltd. EMT Network (2017).Competence framework. https://ec.europa.eu/info/sites/info/ files/emt competence_fwk_2017_en_web.pdf (accessed 01/03/2020).

[10] Fulford, H. \& Granell-Zafra, J. (2005). Translation and technology: A study of UK freelance translators. The Journal of Specialized Translation, (4), 2-17.

[11] Fulford, H. \& Granell-Zafra, J. (2004). The freelance translator's workstation: An empirical investigation. In Proceedings of Foundation for International Studies (pp. 53-61). http://mt-archive.info > EAMT-2004-Fulford (accessed 16/10/2019).

[12] Granell, X. (2015). Multilingual information management: Information, technology and translators. Kidlington, OX: Chandos Publishing.

[13] Hazbavi, A. A. (2011). Investigating the effect of translation memory on English into Persian translation. World Applied Sciences Journal 15.5, 683-689.

[14] Hutchins, J. (2009). Compendium of translation software: Commercial machine translation systems and computer-aided translation support tools (15 $5^{\text {th }}$ ed.). Geneva: European Association for Machine Translation.

[15] Hutchins, J. (1998). The origins of the translator's workstation. Machine Translation 13.4, $287-307$.

[16] Hutchins, J. \& Somers, H. (1992). An introduction to machine translation. San Diego: Academic Press.

[17] Kafi, M., Khoshsaligheh, M., \& Hashemi, M. R. (2018). Translation profession in Iran: Current challenges and future prospects. The Translator 24.1, 89-103.

[18] Ketola, A. \& García-Escribano, A. B. (2018). Social media platforms in translator training. Trans-Kom 11.2, $183-200$.

[19] Khadivi, S. \& Vakil, Z. (2012, December). Interactive-predictive speech-enabled computer-assisted translation. In Proceedings of COLING 2012 (pp. 237-243). http://www.mt-archive.info > IWSLT-2012-Khadivi (accessed 28/09/2019).

[20] Krüger, R. (2016). Contextualizing computer-assisted translation tools and modelling their usability. Trans-Kom 9.1, 114-148.

[21] Locke, N. A. (2005). In-house or freelance? A translator's view. MultiLingual Computing \&Technology 16.1, 19-21.

[22] Maleki, M. \& Tabrizi, H. H. (2017). A corpus-based study of human-translated vs. machine-translated texts: The case of ellipsis in English-Persian translation. Journal of Applied Linguistics and Language Research 4.1, 290-303.

[23] Martikainen, M. (2018). Creation of agile terminology management process and tool for bilingual agile software company. Unpublished M.A. thesis. Oulu University of Applied Sciences, Finland.

[24] Melby, A. (1982). Multi-level translation aids in a distributed system. In J. Horecký (ed.) Proceedings of COLING 82 (pp. $215-$ 220). http://www.aclweb.org > anthology (accessed 11/10/2019).

[25] Mossop, B. (2006). Has computerization changed translation? Meta 51.4, 787-805.

[26] Muñoz, I. (2010). Meeting translators' needs: translation-oriented terminological management and applications. The Journal of Specialized Translation 18, 77-93.

[27] Newton, J. (ed). (1992). Computers in translation: A practical appraisal. London: Routledge.

[28] O'Brien, S. (2006). Eye tracking and translation memory matches. Perspectives: Studies in Translatology 14.3, $185-205$.

[29] PACTE Group (2000). Acquiring translation competence: Hypotheses and methodological problems in a research project. In A. Beeby, D. Emsinger, \& M. Presas (eds.), Investigating translation. Amsterdam: John Benjamins, 99-107.

[30] Pym, A. (2011). What technology does to translation. The International Journal for Translation \& Interpreting Research 3.1, $1-9$.

[31] Quah, C.K. (2006). Translation and technology. New York: Palgrave MacMillan.

[32] Shahri, N. N. \& Farimani, Z. B. (2016). A students' needs-analysis for translation studies curriculum offered at master's level in Iranian universities. IJRELT 4.1, 26-40.

[33] Sharif, F. D. (2016). Evaluation of the translation competency areas in the Iranian national translators' training curriculum. International Journal of Innovation and Research in Educational Sciences 3.6, 340-349.

[34] S. Koby, G., Fields, P., Hague, D., Lommel, A., \& Melby, A. (2014). Defining translation quality. Revista Tradumàtica: tecnologies de la traducció 12, 413-420.

[35] Taghizadeh, M. \& Maryam, A. (2017). Exploring computer-aided translation competences of some Iranian translators. International Journal of English Language \& Translation Studies 5.1, 78-87.

[36] Tantuğ, A. C. \& Adal1, E. (2018). Machine translation between Turkic languages. In K. Oflazer \& M. Saraçlar (eds.) Turkish natural language processing. New York: Springer, 237-254

[37] Taravella, A. \& O. Villeneuve, A. (2013). Acknowledging the needs of computer-assisted translation tools users: The human perspective in human-machine translation. The Journal of Specialized Translation 19, 62-74.

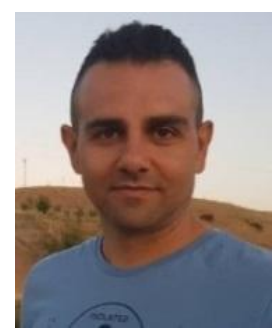

Hamidreza Abdi has MA in Translation Studies from Azad University, Science and Research, Tehran, Iran in 2016. He received his BA in the same major from Azad University, Roodehen, Iran in 2009. He is a freelance researcher in the field of Translation Studies. He has also published numerous articles in different areas of translation. His main interest is research in translation and technology. 